\title{
Incidence Data of Childhood-Onset Type I Diabetes in France During 1988-1997: The Case for a Shift Toward Younger Age at Onset
}

\author{
MARIE-LAURE CHARKALUK, PAUL CZERNICHOW, AND CLAIRE LÉVY-MARCHAL
}

INSERM U 457, Robert Debré Hospital, Paris, France

\begin{abstract}
The objective was to test whether the pattern of increase in incidence of type I diabetes in children under $20 \mathrm{y}$ of age varies with age at onset in France during 1988-1997. The French register of insulin-dependent diabetes was based on the direct identification of new cases by a prospective registration in children under the age of $20 \mathrm{y}$. Data from the French Social Security were used as a secondary independent source of cases. The rate of ascertainment was $\geq 95 \%$ over the 10 -y period studied. Data were analyzed using linear regression; departure from a linear trend was tested in each age group. A total of 1867 children under $20 \mathrm{y}$ of age at the time of diagnosis were included. The incidence rate of type I diabetes in children rose significantly between 1988 and 1997, from 7.41 per 100,000 per year $(95 \%$ confidence interval: $6.55-8.27)$ to 9.58 per 100,000 per year (95\% confidence interval: $8.64-10.52$ ) with $p=0.0001$. The percentage increase was greates in the $0-4$ y age group, with a
\end{abstract}

ABSTRACT

significant departure from linear trend $(p=0.036)$, reflecting an acceleration of the increase. Incidence rates rose linearly in 5-9 y (average increase 0.43 per 100,000 per year, $p=0.011$ ) and $10-14$ y (average increase 0.40 per 100,000 per year, $p=0.002$ ) age groups, whereas it remained stable in the 15-19 y age group $(p=0.77)$. The incidence rate was significantly higher in boys than in girls $(p=0.005)$, but the rise in incidence did not differ between the two genders. The rise in incidence of type I diabetes in France was of the same magnitude as observed in the rest of Europe over $10 \mathrm{y}$. A specific pattern was observed in children under $5 \mathrm{y}$ of age, contrasting with stable rates over $15 \mathrm{y}$. These data suggest a shift toward a younger age at onset of type I diabetes in childhood, contributing, at least in part, to the observed increase in incidence of type I diabetes in children. (Pediatr Res 52: 859-862, 2002)
A rise in incidence rates of childhood-onset type I diabetes has been reported in recent years in children under $15 \mathrm{y}$ of age at diagnosis. The evaluation performed by the large European network EURODIAB has shown an annual increase of 3.2\% between 1989 and 1998 (1), confirming that the increase in incidence in children is real. Among the children under $15 \mathrm{y}$ of age, the rise in incidence seems to be higher in the youngest children. This has been described in some studies performed in more restricted areas with a longer period of observation (2-5), and has recently been confirmed by EURODIAB. The question arises whether the observed increase in incidence rates in childhood reflects an actual rise in the frequency of the disease over lifetime, or whether there is a shift toward a younger age

Received April 8, 2002; accepted July 24, 2002.

Correspondence: Claire Lévy-Marchal, INSERM U 457, Robert Debré Hospital, 48 boulevard Sérurier, F75019 Paris, France; e-mail: clairelm@idf.inserm.fr

M.L.C. was the recipient of a research fellowship by the Assistance Publique/Hôpitaux de Paris (Paris, France). This work was supported by a joint grant from the Direction de la Santé et Institut National de la Santé et de la Recherche Médicale (Paris, France) from 1990 to 1994. This study was part of the EURODIAB network, supported by grants from the European Union (European Community Concerted Action Program: Grants BMH1CT92-0043 and BMH4-CT96-0577).

DOI: 10.1203/01.PDR.0000034261.44203.26 at onset of type I diabetes, reflecting a more aggressive form of the autoimmune disease. Because no data on incidence trends of type I diabetes over lifetime are available, it is impossible to draw a conclusion based on current knowledge.

The French register of incidence of insulin-dependent diabetes in children registered cases occurring under the age of 20 y from 1988 to 1997 . The aims of this study were to quantify the increase of incidence of type I diabetes in children, with a particular interest for the $0-4$ y age group, and to describe the incidence trend in the $15-19$ y age group.

\section{SUBJECTS AND METHODS}

Registration of cases. The functioning of the French register of incidence of insulin-dependent diabetes has been described in detail elsewhere (6). This prospective registration met the inclusion criteria of the EURODIAB Study, using two direct and independent sources of identification of cases (7). The various hospital units for adults and children as well as private hospitals and practitioners in private practice were selected as the primary source of information. Data of the French national health insurance (Social Security) was the secondary independent source of identification of cases. The rate of ascertainment 


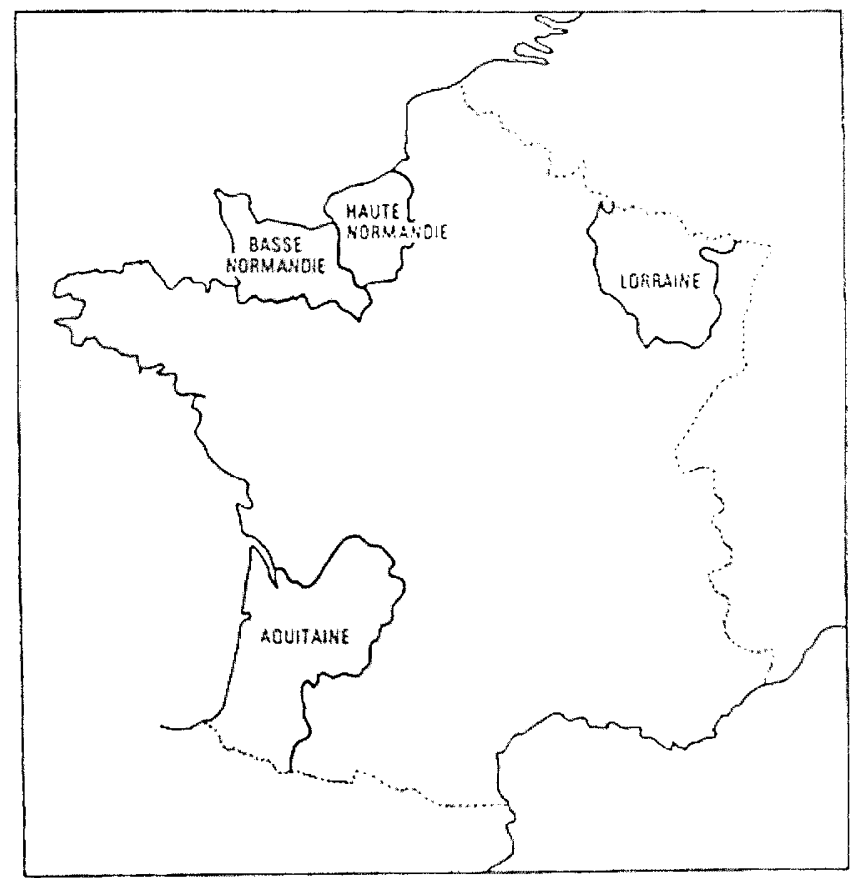

Figure 1. Map of France with the four counties included in the study $\left(94,800 \mathrm{~km}^{2}\right)$.

of cases was calculated using the "capture recapture" method (8), and was $>95 \%$ over the study period (9). The register was operated between January 1, 1988, and December 31, 1997. All cases of type I diabetes occurring between these two dates were included. Type I diabetes was diagnosed accorded to the World Health Organization criteria (10), together with a permanent need for insulin therapy, and secondary cases were excluded. As illustrated in Figure 1, the study areas covered four French counties: Aquitaine, Lorraine, Basse-Normandie, and HauteNormandie, covering a population of more than 2 million subjects aged $<20 \mathrm{y}$. These four counties reflect the diversity of the French population. For example, Basse-Normandie and Aquitaine are more rural and Haute-Normandie and Lorraine are more industrial areas. The population density was lowest in Basse-Normandie. The study area includes three cities of more than 300,000 inhabitants.

Calculation of incidence rates. The numerators were made by all cases identified by either source.
Age was calculated for each individual as the full attained age on the first day of insulin therapy. The population numbers were provided by the Institut National de la Statistique et des Etudes Economiques (INSEE). They are available for each age group, for both genders, and for each county for each of the 10 individual years of the study (11). Details for the study population can be seen in Table 1 for the first and the last years of the study, as an indicative example.

Incidence rates were calculated for the overall study population, for each age group (0-4 y, 5-9 y, 10-14 y, and 15-19 $y)$, and for each gender. Standardized incidence rates were calculated based on a direct standardization assuming the standard population to be distributed in groups of equal size, defined by age groups and/or gender.

Statistical analysis. The trend in incidence rates was tested using a linear regression, where the standardized incidence rate was the dependent variable and the calendar year the independent variable. In each age group, a departure from linear trend

Table 1. Overall and sex-specific incidence rates

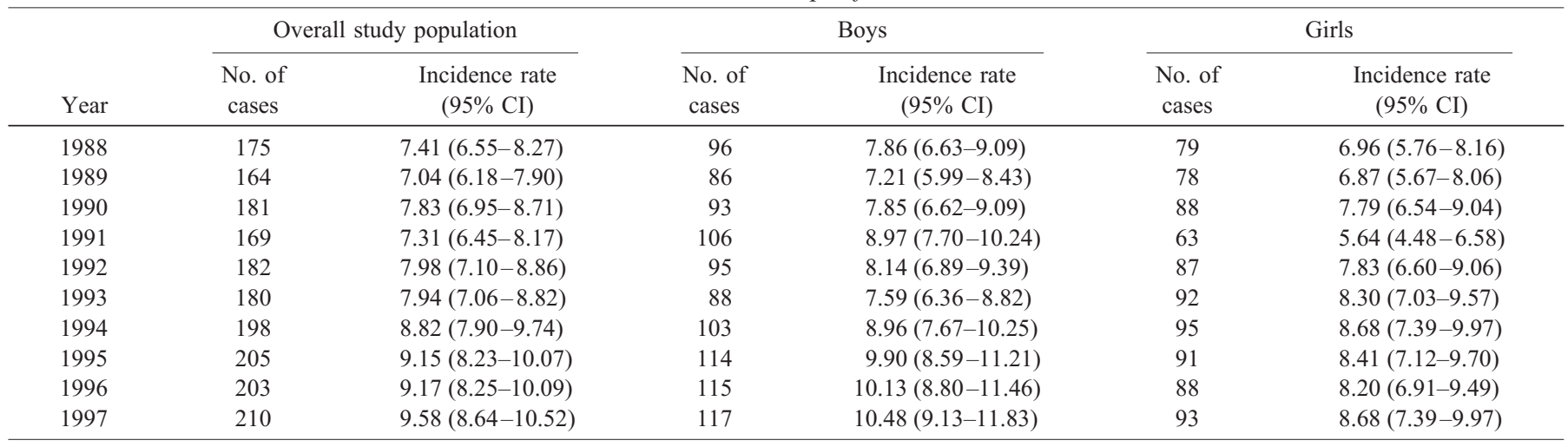

Yearly age- and sex-adjusted incidence rates for the overall study population (number of cases per 100 000), and yearly age-adjusted incidence rates in boys and in girls (number of cases per 100000 ) of type I diabetes in children aged under $20 \mathrm{y}$, in four counties of France during $1988-1997$. 
Table 2. Study population in the first and the last years of the study

\begin{tabular}{lccccc}
\hline & \multicolumn{2}{c}{1988} & & \multicolumn{2}{c}{1997} \\
\cline { 2 - 3 } \cline { 6 - 6 } & Boys & Girls & & Boys & Girls \\
\hline 0-4 y & 281664 & 269277 & & 252525 & 241850 \\
$5-9$ y & 291852 & 277475 & & 278839 & 266347 \\
$10-14$ y & 300768 & 286278 & & 289665 & 278446 \\
$15-19$ y & 332237 & 316174 & & 290120 & 275372 \\
\hline
\end{tabular}

Population at risk during the first and the last years of the study in each age group for the two genders.

was tested by comparing two models: one with the calendar year, and one with the calendar year together with the square of this variable.

For the analysis by gender, the parallelism of the linear regression lines fitted in each group was tested. An analysis of covariance was performed if the slopes could be considered as equal.

The analyses were performed using the STATA statistical software release 7.0 (Stata Corporation College Station, TX, U.S.A.).

\section{RESULTS}

A total of 1867 eligible patients were included in the present study (Table 2).

In the overall population, the age- and sex-adjusted incidence rate increased from 7.41 per 100,000 per year $[95 \%$ confidence interval (CI): 6.55-8.27] in 1988 to 9.58 per $100,000$ per year (95\% CI: $8.64-10.52)$ in 1997 . The average increase was 0.28 per 100,000 per year (95\% CI: $0.19-0.36$; $p$ $=0.0001)$. There was no significant departure from linear trend $(p=0.17)$. As shown in Figure 2, the percentage rise in incidence was greatest in the $0-4$ y age group, whereas the sex-adjusted annual incidence was 4.17 per 100,000 per year (95\% CI: 2.64-5.70) in 1988 and 7.48 per 100,000 per year (95\% CI: 5.63-9.27) in 1997. Consequently, an increase of $78 \%$ was observed over $10 \mathrm{y}$ in this age group. A significant departure from linear trend was found $(t=2.58, p=0.036)$. In none of the other age-groups was a significant departure from linear trend observed. Incidence rates rose linearly and significantly in the $5-9$ y $[0.43 / 100,000 / y(95 \%$ CI: $0.13-$ $0.74), p=0.011]$ and $10-14$ y $[0.40 / 100,000 / y(95 \% \mathrm{CI}$ : $0.20-0.60), p=0.002]$ age groups. In contrast, there was no significant change in incidence rates in the $15-19$ y age group, with a regression slope of -0.02 per 100,000 per year $(95 \%$ CI: -0.18 to $0.14, p=0.77)$. The annual increase was $4.2 \%$ per year (95\% CI: $2.8-5.5)$ in the $0-14$ y age group.

The rise in incidence was not statistically different between the two genders $(p=0.20)$, but a consistently higher incidence rate over years was found in boys in comparison to girls (analysis of covariance: $F_{1,17}=10.15, p=0.005$ ).

There were no statistically significant differences in incidence rates between the four counties over the study. The only difference was that no statistically significant increase could be seen in Basse-Normandie over the study period, whereas the other three counties showed indeed a significant increase of comparable magnitude.
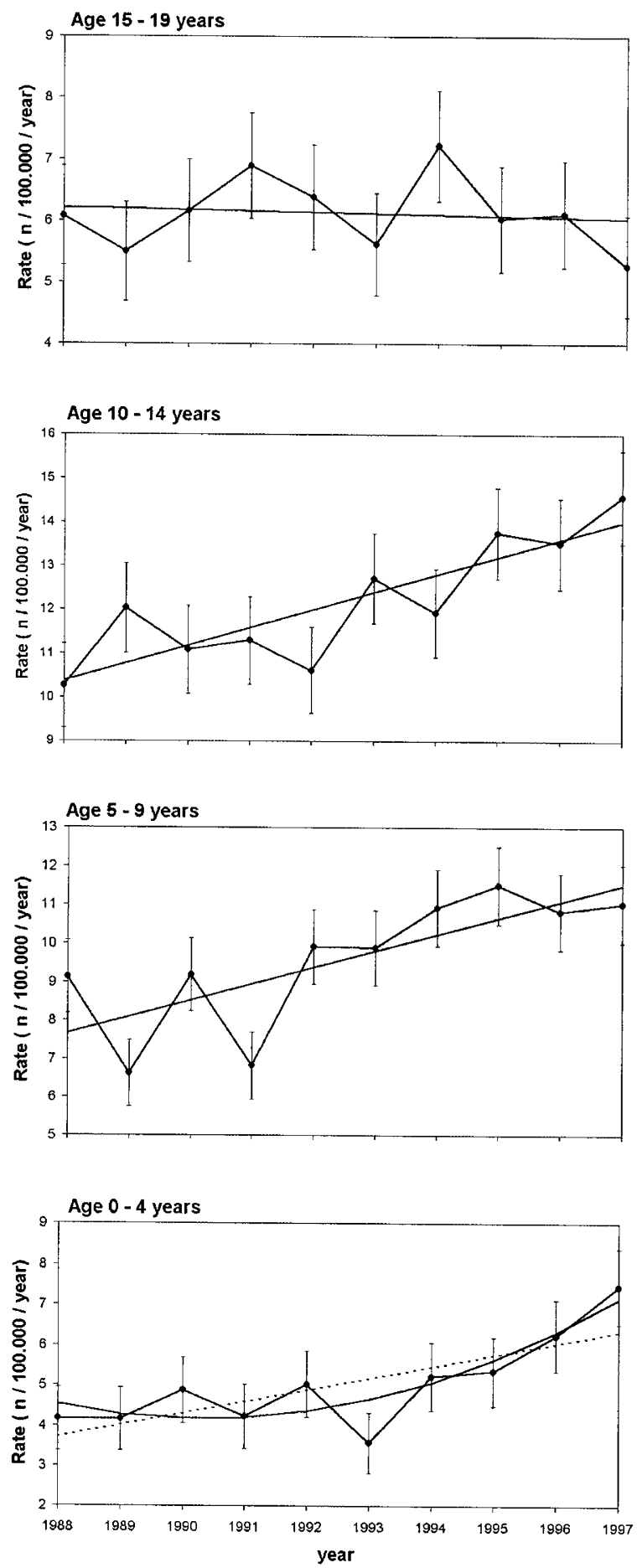

Figure 2. Time course of incidence rates across age groups. Sex-adjusted incidence rates (number of cases/100,000/y \pm SD) of type I diabetes in children aged 0-4, 5-9, 10-14, and 15-19 y in France during 1988-1997, together with the regression curve when a significant departure from linear trend was seen (for the $0-4$ y age group), or the regression line (solid line) when no significant departure from linear trend was seen (for the 5-9, 10-14, and $15-19$ y age groups). In the bottom panel, the dotted line is the regression line for $0-4$ y age group.

\section{DISCUSSION}

This 10-y study of incidence of type I diabetes in children shows an increase in incidence rates in France at the same 
order of magnitude as in other European countries. Nevertheless, a specific pattern of increase was found in the $0-4$ y age group, contrasting with stable rates in the 15-19 y age group. The increasing number of cases registered under the age of $15 \mathrm{y}$ could not be explained by a change in the definition of type I diabetes, by a general-population screening, or by a reduced number of deaths at onset before registration because no major modification in the health care system had taken place over the period of the study in this country. Therefore, those prospective incidence data clearly confirm the rise in incidence of type I diabetes in children that was observed in the most recent studies $(2,4,5)$.

Despite the steeper rise in incidence in children aged $0-4 \mathrm{y}$, this increase in the youngest age group does not entirely account for the overall rise in incidence of type I diabetes, since a significant increase was also observed in the 5-9 y and $10-14$ y age groups. This makes the epidemiologic situation different from that observed in Switzerland (5), where the rise in incidence of type I diabetes in children below $15 \mathrm{y}$ of age was entirely due to the contribution of the $0-4$ y age group between 1991 to 1999 .

Our data show that the incidence remained stable in the 15-19 y age group. This age group has been rarely studied. In agreement with our observation, a Polish study showed no modification of incidence in the 15-29 y age group from 1994 to 1998 , whereas an increase was seen below 15 y of age (12).

The specific pattern of rise in incidence rates of type I diabetes that is therefore observed for the first time suggests a shift toward a younger age at onset of the disease. Some evidence for such a shift has been given by studies showing the greatest increase in the youngest age groups, namely EURODIAB (1) and studies in Finland (3), the United Kingdom (2), and Switzerland (5). Furthermore, a Swedish cohort study documented a shift toward a younger age at onset of type I diabetes among children under 15 y (4).

Such an increase in incidence of type I diabetes over a period of 10 years does not reflect a modification in the genetic background of the study population. More likely it suggests that environmental factors interact with a genetic susceptibility and lead to a more aggressive form of the disease with an earlier age at onset of the clinical disease.

\section{CONCLUSION}

Incidence rates of type I diabetes rose in France between 1988 and 1997 for children below 15 y of age, with a specific pattern of acceleration in children below $5 \mathrm{y}$ of age. The incidence rates were stable in the 15-19 y age group. This specific pattern of increase argues for a shift toward a younger age at onset, which contributes, at least in part, to the observed increase in incidence of type I diabetes in children. This might be explained by the role of early environmental events in highly genetically susceptible children. Further studies are needed to assess the evolution of incidence rates in the adult population to confirm this hypothesis.

Acknowledgments. The authors thank the physicians at the Medical Department of Caisse Nationale de l'Assurance Maladie des Travailleurs Salariés (CNAMTS) for their valuable contribution to the register. We also thank all the physicians involved in the register network for their fruitful participation.

\section{REFERENCES}

1. Green A, Patterson C on behalf of the EURODIAB TIGER Study Group 2001 Trends in the incidence of childhood-onset diabetes in Europe 1989-1998. Diabetologia 44:B3-B8

2. Gardner SG, Bingley PJ, Sawtell PA, Weeks S, Gale EAMG 1997 Rising incidence of insulin-dependent diabetes in children aged under 5 years in the Oxford region: time trend analysis. BMJ 315:713-717

3. Karvonen M, Pitkäniemi J, Tuomilehto J, and The Finnish Childhood Diabetes Registry Group 1999 The onset age of type I diabetes in Finnish children has become younger. Diabetes Care 22:1066-1070

4. Dahlquist G, Mustonen L 2000 Analysis of 20 years of prospective registration of childhood onset diabetes - time trends and birth cohort effects. Acta Paediatr 89:1231-1237

5. Schoenle EJ, Lang-Muritano M, Gschwend G, Laimbacher J, Mullis PE, Torresani T, Biason-Lauber A, Molinari L 2001 Epidemiology of type I diabetes mellitus in Switzerland: steep rise in incidence in under 5 years old children in the past decade. Diabetologia 44:286-289

6. Lévy-Marchal C, Papoz L, Beaufort CD, Doutreix J, Froment V, Voirin J, Collignon A, Garros B, Schleret Y, Czernichow P 1990 Incidence of juvenile type I (insulindependent) diabetes mellitus in France. Diabetologia 33:465-469

7. Green A, Gale EAM, Patterson CC 1992 Incidence of childhood-onset insulindependent diabetes mellitus: the EURODIAB ACE study. Lancet 339:905-909

8. Hook EB, Regal RR 1992 The value of capture-recapture methods even for apparent exhaustive surveys. Am J Epidemiol 135:1060-1067

9. The EURODIAB ACE Study Group 2000 Variation and trends in incidence in childhood diabetes in Europe. Lancet 355:873-876

10. World Health Organization Expert Committee on Diabetes Mellitus 1980 Second Report. Technical Report Series. WHO, Geneva

11. Estimations localisées de population (Séries 1975-1997) Institut National de la Statistique et des Etudes Economiques. CD-rom EL:7597

12. Kretowski A, Kowalska I, Peczynska J, Urban M, Green A, Kinalska I 2001 The large increase in incidence of type I diabetes mellitus in Poland. Diabetologia 44:B48-B50 